\title{
An Improved Portfolio Optimization Model for Oil and Gas Investment Selection Considering Investment Period
}

\author{
Siying Huang \\ School of Business Administration, South China University of Technology, Guangzhou, China \\ Email: huangsiying0310@163.com
}

How to cite this paper: Huang, S.Y. (2019) An Improved Portfolio Optimization Model for Oil and Gas Investment Selection Considering Investment Period. Open Journal of Social Sciences, 7, 121-129. https://doi.org/10.4236/jss.2019.71011

Received: December 21, 2018

Accepted: January 13, 2019

Published: January 16, 2019

Copyright ( 2019 by author(s) and Scientific Research Publishing Inc. This work is licensed under the Creative Commons Attribution International License (CC BY 4.0).

http://creativecommons.org/licenses/by/4.0/

\section{(c) (7) Open Access}

\begin{abstract}
Due to the suddenness, uncertainty and huge loss of political risks in overseas projects, this paper considers the time dimension and the success rate of project exploitation for the goal of optimizing the allocation of multiple objectives, such as output, investment, efficiency and risk. A linear portfolio risk decision model is proposed for multiple indicators, such as the uncertainty of project survey results, the inconsistency of project investment time, and the number of projects in unstable political regions. The model is tested by numerical examples and the results show that the model can effectively maximize the portfolio income within the risk tolerance range under the premise of ensuring the rational allocation of resources.
\end{abstract}

\section{Keywords}

Investment Period, Success Rate, Portfolio, Oil and Gas

\section{Introduction}

Since the 1990s, many international oil companies have continuously developed systemic risk analysis and optimized portfolio technology to avoid or reduce exploration risks, which is one of the hotspots in the international petroleum industry in recent years [1]. Many companies use net present value to evaluate exploration and production projects to enhance their investment decisions [2] [3] [4]. However, the optimal choice of a single project may not be the best option to achieve the company's overall minimum risk and maximum return. Although NPV is still a key criterion for most capital allocation processes, NPV has difficulty analyzing long-term, large hidden internal costs and various risk appetite projects for investors. As a result, oil companies began to analyze "over the NPV" 
with emphasis on key performance indicators and uncertainties [5] [6] [7]. Oil and gas development are highly uncertain. The benefits and risks of different oilfields will vary depending on the source properties, geological understanding, and mining techniques. Oil and gas development are highly uncertain. The benefits and risks of different oilfields will vary depending on the source properties, geological understanding, and mining techniques. These uncertainties increase the risk of oil companies mining, which is difficult to measure. Whether oil and gas development projects are worth investing has added some difficulty to investment decisions. With a better understanding of geology and geophysics, a better estimate of cash flow allows the project to be ranked according to conventional measures, such as expected monetary value or expected net present value.

For state-owned oil companies, some private and joint ventures, their financial strength is relatively strong and financing is relatively easy. The pursuit of oil and gas projects is often the pursuit of maximum return on investment at a certain level of risk. While for those with weak financial strength and relatively difficult financing, it is often pursued to minimize the risk under certain conditions of expected returns. In the long run, in either case, companies aim to pursue the least risk and maximize the return on investment. How to balance the relationship between income and risk to maximize the overall income is an urgent problem we need to solve.

\section{Establishment of Investment Portfolio Optimization Model for Oil and Gas Development Projects}

In the early development of oil and gas resources, the most important issue for oil companies is how to invest in different oilfield development projects each year with limited development investment budget. The entire investment allocation decision process of oil and gas resources development has high risk, high complexity and high uncertainty. Once the decision is wrong, the oil company will suffer huge economic losses and irreversible damage to the environment. Under normal circumstances, the company predicts the proven reserves of oil and gas in different oilfield projects based on data collected from exploration work such as exploration and drilling in the previous period. At the beginning of the investment period, according to the available development investment quota, the investment portfolio decision is made for each oilfield development project to achieve different target needs such as high investment income, low mining cost and low investment risk.

\subsection{Model Assumptions}

1) Once the oil and gas project begin to be mined, it is generally not closed. It still needs to invest a certain amount of resources to keep it running every year. However, in special circumstances, it is allowed to temporarily stop the project. For example, if the oil and gas market prices continue to be mined at a very low level, the company will suffer serious losses or it will lead to environmental 
damage if keep on mining.

2) Residual values are not considered when each project fails to mine. Equipment and infrastructure inputs in the pre-exploration phase of the project are considered as sunk costs, regardless of their residual value.

3) If the project is evaluated to prove that the project is technically feasible and economically reasonable, the project will be developed immediately, without considering other factors causing delays in development. If development delays due to other factors, the project is not part of the development portfolio.

4) The project investment ratio has a linear relationship with the project income, that is, the investment scale does not increase the complexity of the capital allocation process.

5) The recoverable reserves of oil and gas fields are limited by geological, technical and other conditions, so there is a limit on the maximum recoverable reserves. However, since oil and gas exploration and development are centered on economic benefits, when the margin of oil and gas exploitation is less than the marginal cost, mining is stopped. At this time, the cash flow is the best cash flow, and the project has the largest net present value.

\subsection{Model Construction}

The capital expenditure of oil and gas enterprises in project investment is mainly divided into two stages. The initial investment of oil and gas enterprises in the exploration and development stage is divided into development wells, ground works, and filling and side drilling inputs. Among them, the development well investment mainly refers to the cost of drilling, logging, cementing, completion, oil testing and related technology and management. The ground engineering refers to the investment of production equipment which requires large-scale enterprises capital investment [8]. While capital investment after the success of the survey is usually divided into material costs, power costs, transportation costs, operating fees. Therefore, oil and gas enterprises need large-scale capital inflows in the early stage of investment. When the development is successful, a small amount of capital investment is still needed to maintain stable capital income. In the project selection problem, it is usually assumed that the initial expenditure occurs at the beginning of the month and the net cash flow occurs at the end of the month [9]. In addition, we assume that companies need to make investment decisions at the beginning of the investment period. Therefore, the development cash flow of the oil and gas project is shown in Figure 1, where $s_{i}$ indicates the project investment start time. When $s_{i}=0$, the project starts from now; When $s_{i}=t$, the project starts from the $t$ month. $\gamma_{i}$ Indicates the investment period of the project $i$, which requires large-scale capital investment by the enterprise, and $O_{i t}$ is the amount of capital invested in each period. When the development is successful, $\tau_{i}$ indicates the project is payback period, and still needs a small amount of capital investment $O_{i t}$ to maintain a stable capital income $I_{i t}$.

In fund management, returns are usually expressed on a year-by-year basis, 


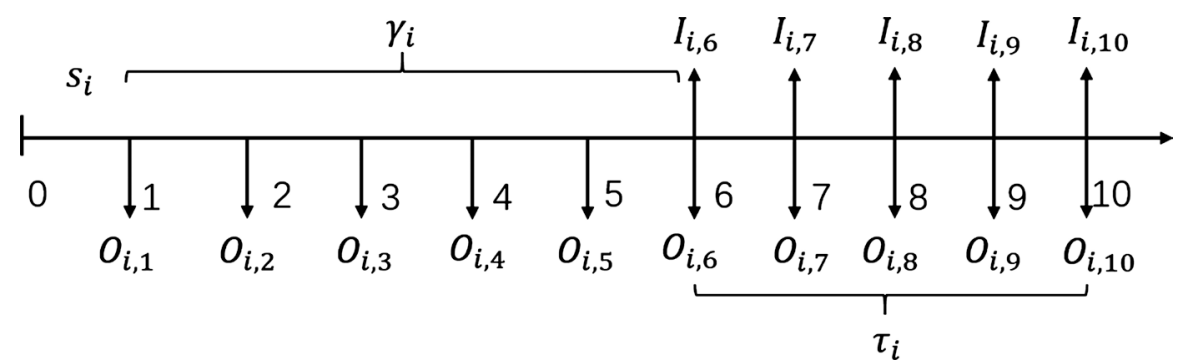

Figure 1. The figure of Project i's cash flow.

but in the oil and gas industry, the feasibility and return of the project is usually compared based on expected monetary value (EMV) [10] or expected net present value (ENPV) [11]. The EMV approach recognizes the uncertainty of the project and attributes the value to different outcomes. Therefore, the EMV estimation method can be considered as a dynamic method and is superior to the traditional static method like net present value method which only has one result. Guj (2006) describes EMV as the mean of the distribution which equal to the sum of all possible NPV values plus the probability of their respective occurrence. Due to the complexity and uncertainty of oil and gas resources exploration and development, the incompleteness of the understanding of the geological properties of oil and gas resources buried in the underground may result in the failure of dry wells and drilling.

$$
R_{i}=-\sum_{t=s_{i}}^{\gamma_{i}} \frac{O_{i t}}{(1+r)^{t}}+\sum_{t=\gamma_{i}}^{\gamma_{i}+\tau_{i}} \frac{I_{i t}-O_{i t}}{(1+r)^{t}} p_{i} .
$$

where $\gamma_{i}$ is the initial investment period of project $i ; \tau_{i}$ is the income period of project $i ; R_{i}$ is the investment income of project $i ; I_{i t}$ is the cash inflow of project $i$ for period $t, O_{i t}$ is the cost for the later part of project $i$ in period $t, p_{i}$ is the probability of successful mining for the project $i$.

In addition, international projects are susceptible to political risks when investing in overseas oilfield projects. Because of the suddenness, uncertainty, and loss of political risks, it is difficult for companies to effectively prevent them. For example, the contradiction or sanctions arising from the host country and the country due to trade problems have worsened relations between the two countries. In order to retaliate, the host government may impose restrictions on the projects it invests in the country, resulting in production disruption [5]. Therefore, when investing in politically unstable countries, it is necessary to limit the number of projects invested in the region to achieve the dispersion of investment risks. For example, considering the political and economic risks of resource countries in the Middle East, investment in Middle East projects needs to be limited in the portfolio. Therefore, the following constraints are established:

$$
\sum_{i=1}^{n}\left(\text { zone }_{i, a} \cdot x_{i}\right) \leq c, a \in \text { ZONE . }
$$

where zone $_{i, a}$ is the area where the project $i$ is located is area $a ; c$ is the number of investment projects of area $a$; ZONE is the area set of the alternative item set. 
In the international oil and gas mergers and acquisitions sector, there is a special type of agreement for the exploration rights purchase/transfer agreement. From the perspective of the transferor of exploration share rights, due to the risk investment and technical risks of oil and gas exploration and development, it is necessary to introduce partners to share the capital risk of exploration. From the perspective of the purchaser of exploration rights, the purchase of exploration rights is conducive to the rapid acquisition of seismic and drilling data related to hotspots or emerging areas, as well as access to exploration mines or commercial discovery reserves [12]. Since the oil industry is an industry that is related to the lifeline of the national economy, the oil and gas producing countries set the highest proportion of production and management rights for foreign companies engaged in oil and gas production activities, or set the minimum limit for holding domestic companies. To maintain energy sovereignty, such as Venezuela's policy on the regulation of petroleum resources, overseas investment companies must form a joint venture with the Venezuelan National Oil Company and be under the control of the Venezuelan National Oil Company for oil exploration and development [13]. Therefore, this paper considers two situations in which oil companies invest in domestic and overseas projects. Use $w_{i}$ as the investment ratio. When $w_{i} \subset[0,1]$, project $i$ is a domestic project; when $w_{i} \subset[0,1]$, project $i$ is an overseas project.

Consider maximizing the return on investment at a certain level of risk and establish the following model:

$$
\left\{\begin{array}{l}
\max \frac{1}{n} \sum_{i=1}^{n} w_{i} R_{i} x_{i} \\
\text { s.t. } \frac{1}{n} \sum_{i=1}^{n}\left(\min \left\{0, w_{i} R_{i} x_{i}-\frac{1}{n} \sum_{i=1}^{n} w_{i} R_{i} x_{i}\right\}\right)^{2} \leq \alpha \\
R_{i}=-\sum_{t=s_{i}}^{\gamma_{i}} \frac{O_{i t}}{(1+r)^{t}}+\sum_{t=\gamma_{i}}^{\gamma_{i}+\tau_{i}} \frac{I_{i t}-O_{i t}}{(1+r)^{t}} p_{i} \\
\sum_{i=1}^{n} q_{i t} x_{i} \geq y_{t}, t=1,2, \cdots, T \\
\sum_{i=1}^{n} O_{i t} x_{i} \leq b_{t}, t=1,2, \cdots, T \\
\sum_{i=1}^{n} c_{i t} x_{i} \leq h_{t}, t=1,2, \cdots, T \\
\sum_{i=1}^{n} x_{i} \leq b, t=1,2, \cdots, T \\
s_{i}+\gamma_{i}+\tau_{i} \leq D \\
x_{i} \in\{0,1\} ; s_{i} \in\{1,2, \cdots, T\}
\end{array}\right.
$$

where $\alpha$ is the maximum risk level acceptable to the enterprise; $q_{i t}, O_{i t}, c_{i t}$ is the expected output, investment amount, production and operation cost of the project $i$ in the period $t, y_{t}, b_{t}, h_{t}$ is the minimum production requirement of the enterprise in the $t$ period, the total development investment budget, and the maximum allowable productivity respectively; $b$ is the limit for the maximum 
number of investments; $D$ the total investment period.

\section{Numerical Examples}

In order to illustrate the modeling ideas and prove the validity of the designed model, we present a numerical example here. Assume that a company is considering to select some project among 10 reserve trap targets, among which projects $1,2,3,4$, and 10 are overseas development projects, and the remaining projects are domestic development projects. The investment length, operating life, monthly initial expenditure, and monthly net of each project cash flow data is shown in Table 1 , where $w_{i}$ is the investment ratio. When $w_{i} \subset[0,1]$, project $i$ is a domestic project; when $w_{i} \subset[0,1]$, project $i$ is an overseas project. $\gamma_{i}$ Indicates the investment period of the project $i$, which requires large-scale capital investment by the enterprise, and $O_{i t}$ is the amount of capital invested in each period. When the development is successful, $\tau_{i}$ indicates the project $i s$ payback period, and still needs a small amount of capital investment $O_{i t}$ to maintain a stable capital income $I_{i t}$.

The regional information, estimated production, production and operation costs and development probability data of each project in different periods are shown in Table 2, where zone is the area where project $i$ is located. $q_{i t}, O_{i t}, c_{i t}$ is the expected output, investment amount, production and operation cost of the project $i$ in the period $t . p_{i}$ is the probability of successful mining for the project $i$.

The company can provide 500,000 US dollars of investment per month, and the total number of investment projects should not exceed 5; the number of projects with zone 1 should not exceed 3; the investment risk should not exceed 1102; the newly added reserves should not be less than 150,000 tons. The operating cost cannot be greater than $\$ 85,000$. Taking the above requirements as

Table 1. The investment length, operating life and net cash inflow data of the project.

\begin{tabular}{|c|c|c|c|c|c|c|c|c|}
\hline \multirow{2}{*}{$i$} & \multirow{2}{*}{$w_{i}$} & \multirow{2}{*}{$\gamma_{i}$} & \multirow{2}{*}{$\tau_{i}$} & \multicolumn{2}{|r|}{$O_{i t}$} & \multicolumn{3}{|c|}{$I_{i t}$} \\
\hline & & & & $s_{i} \leq t \leq s_{i}+\gamma_{i}$ & $s_{i}+\gamma_{i}<t \leq s_{i}+\gamma_{i}+\tau_{i}$ & $s_{i}+\gamma_{i}<t \leq s_{i}+\gamma_{i}+11$ & $s_{i}+\gamma_{i}<t \leq s_{i}+\gamma_{i}+23$ & $s_{i}+\gamma_{i}+24<t \leq s_{i}+\gamma_{i}+\tau_{i}$ \\
\hline 1 & 0.5 & 3 & 61 & 94.25 & 6.75 & 26.75 & 28.25 & 34.25 \\
\hline 2 & 0.3 & 4 & 76 & 115 & 13.5 & 33.5 & 26.25 & 33 \\
\hline 3 & 0.2 & 5 & 64 & 115 & 17 & 37 & 29.5 & 34.75 \\
\hline 4 & 0.8 & 4 & 74 & 139 & 11.5 & 31.5 & 29.5 & 33 \\
\hline 5 & 1 & 5 & 67 & 140.25 & 13 & 33 & 28.75 & 34.75 \\
\hline 6 & 1 & 5 & 73 & 132.5 & 12.5 & 32.5 & 30 & 35.75 \\
\hline 7 & 1 & 4 & 62 & 137 & 15.25 & 35.25 & 31.5 & 35.5 \\
\hline 8 & 1 & 4 & 72 & 149 & 10.25 & 30.25 & 28.5 & 33 \\
\hline 9 & 1 & 6 & 60 & 127.25 & 13.75 & 33.75 & 29.75 & 35 \\
\hline 10 & 0.6 & 3 & 77 & 132.5 & 11.75 & 31.75 & 27 & 32.25 \\
\hline
\end{tabular}


Table 2. Target economic evaluation result data of project development.

\begin{tabular}{ccccc}
\hline & & $q_{i t}$ & $c_{i t}$ & \\
\cline { 3 - 4 } & zone & $S_{i}+\gamma_{i}<t \leq s_{i}+\gamma_{i}+\tau_{i}$ & $s_{i}<t \leq s_{i}+\gamma_{i}+\tau_{i}$ & \\
\hline 1 & 1 & 1.33 & 11.33 & 0.8 \\
2 & 1 & 1.08 & 11.08 & 1 \\
3 & 1 & 1.50 & 11.50 & 1 \\
4 & 2 & 7.19 & 17.19 & 1 \\
5 & 2 & 13.96 & 23.96 & 0.6 \\
6 & 2 & 3.84 & 13.84 & 1 \\
7 & 3 & 6.45 & 16.45 & 1 \\
8 & 3 & 13.19 & 23.19 & 0.5 \\
9 & 4 & 3.33 & 13.33 & 1 \\
10 & 1 & 5.19 & 15.19 & 0.9 \\
\hline
\end{tabular}

Table 3. Project investment schedule.

\begin{tabular}{cccc}
\hline Item & 1 & 8 & 10 \\
Start time (month) & 0 & 2 & 3 \\
Target value (ten thousand dollars) & & 36.72 & \\
\hline
\end{tabular}

constraints, the company can use the model (3) to obtain the maximum expected profit under risk control. Running the above model to optimize, the company should invest in projects $1,8,10$. The investment schedule is shown in Table 3. The net present value of the maximum expected return is $\$ 367,200$.

\section{Conclusions}

Based on the existing portfolio research of oil and gas projects, this paper establishes a linear portfolio risk decision model based on the theory, characteristics and existing methods of securities portfolio. The model considers the uncertainty of project survey results, the inconsistency of project investment time points, and the number of projects in unstable political regions. Under the premise of ensuring the rational allocation of funds and other resources, the model can maximize the project portfolio income within the risk tolerance range. Finally, the application of the decision model is analyzed by numerical examples. The proposed model has guiding significance for the practice of oil and gas exploration investment decision. The model comprehensively considers the time dimension and the multiple indicators, such as production, investment and benefit risk. In addition, the mathematical relationships between the logical relationships and business rules of each investment unit under the complex contract model are characterized by mathematical statements. Using the model and method established in this paper, we can propose corresponding optimization strategies for multi-objective optimization practices in overseas projects and key 
regions according to different goals and expectations, which lays a theoretical foundation for the construction of overseas strategic planning decision support.

In reality, due to the lack of historical data, some project parameters must be given by experts' estimates. This paper only applies numerical examples to the model. Further research may involve considering more real-life situations and applying the proposed method to actual case problems.

\section{Conflicts of Interest}

The author declares no conflicts of interest regarding the publication of this paper.

\section{References}

[1] Alexandermarrack, P., Ofstad, K. and Kittilsen, E.J. (2000) Improving the Exploration Process by Learning from the Past. New Zealand Journal of Crop \& Horticultural Science, 40, 265-267.

[2] Shu, S.B., Zeithammer, U.R. and Payne, U.J. (2013) Consumer Preferences for Annuities: Beyond NPV. Working Paper.

[3] Wood, D.A. (2016) Characterization of Gas and Oil Portfolios of Exploration and Production Assets Using a Methodology that Integrates Value, Risk and Time. Journal of Natural Gas Science \& Engineering, 30, 305-321. https://doi.org/10.1016/j.jngse.2016.02.030

[4] Xue, Q., Wang, Z., Liu, S., et al. (2014) An Improved Portfolio Optimization Model for Oil and Gas Investment Selection. Petroleum Science, 11, 181-188. https://doi.org/10.1007/s12182-014-0331-8

[5] Liu, B.F. (2009) Research on the Uncertainty of Political Risk in International Petroleum Exploration and Development Projects. Journal of China University of Petroleum (Social Science Edition), 25, 1-4.

[6] Ward, K. and Ryals, L. (2001) Latest Thinking on Attaching a Financial Value to Marketing Strategy: Through Brands to Valuing Relationships. Journal of Targeting, Measurement and Analysis for Marketing, 9, 327-340. https://doi.org/10.1057/palgrave.jt.5740024

[7] Xu, J. (2013) Beyond Expected Value: Integrated Project Valuation for Decision Making under Uncertainty. 75 th EAGE Conference \& Exhibition Incorporating SPE EUROPEC, London, UK, 12-13 June 2013,. https://doi.org/10.2118/164828-MS

[8] Qin, Q.J. and Zhu, H. (2000) Analysis of Low-Cost Strategy of Foreign Large Petrochemical Companies. Petrochemical Technology and Economy, 29, 22-25.

[9] Huang, X., Zhao, T. and Kudratova, S. (2016) Uncertain Mean-Variance and Mean-Semivariance Models for Optimal Project Selection and Scheduling. Knowledge-Based Systems, 93, 1-11. https://doi.org/10.1016/j.knosys.2015.10.030

[10] Hayashi, S.H.D., Ligero, E.L. and Schiozer, D.J. (2010) Risk Mitigation in Petroleum Field Development by Modular Implantation. Journal of Petroleum Science \& Engineering, 75, 105-113. https://doi.org/10.1016/j.petrol.2010.10.013

[11] Al-Harthy, M.H. (2007) Utility Efficient Frontier: An Application in the Oil and Gas Industry. Natural Resources Research, 16, 305-312. https://doi.org/10.1007/s11053-007-9056-3

[12] Tang, B.J., Zhou, H.L. and Cao, H. (2017) Selection of Overseas Oil and Gas 
Projects under Low Oil Price. Journal of Petroleum Science and Engineering, 156, 160-166. https://doi.org/10.1016/j.petrol.2017.05.022

[13] Yuan, Z.Z. (2008) Political Risk Analysis of Latin American Petroleum Investment. International Petroleum Economy, 16, 11-17. 